\title{
A APLICAÇÃO DO PRINCÍPIO DA EFICIÊNCIA À ADMINISTRAÇÃO PÚBLICA: LEVANTAMENTO BIBLIOGRÁFICO E ESTUDO DA JURISPRUDÊNCIA DO TJRS
}

Luciano Benetti Timm*

Giuliano Toniolo**

\section{Resumo}

O princípio da eficiência foi inserido no caput do artigo 37 da Constituição Federal em 04/06/1998. O presente artigo trata de uma revisão bibliográfica sobre o tema produzido no Brasil desde então (o chamado law on the books), além de conter um estudo de caso sobre como o Tribunal de Justiça do Rio Grande do Sul vem interpretando este dispositivo, que consiste no verdadeiro método anglo-americano do common law de pesquisa, focalizando, essencialmente, o direito tal como praticado nas cortes (law in action), o qual, muitas vezes, não coincide com o direito doutrinário.

Palavras-chave: Princípio da eficiência. Constituição Federal. Artigo 37. Serviço público.

\section{Introdução}

A partir do advento da Emenda Constitucional 19/98, é incumbência do gestor público atuar segundo o Princípio da Eficiência. Não se trata de mero princípio agregado ao texto constitucional. Em um país com escassez de recursos econômicos para serem aplicados em diversos setores e necessidades sociais, tratar, eficientemente, dos custos (evitando desperdícios) é questão de justiça social.

O propósito deste artigo é, de um lado, fazer levantamento bibliográfico de qual tem sido a interpretação doutrinária acerca do referido dispositivo constitucional. Como se demonstrará no item 1, a doutrina especializada administrativa entende que eficiência é, via

\footnotetext{
* Pós-doutor pela U.C. Berkeley; doutor em Direitos dos Negócios e da Integração Regional pela Universidade Federal do Rio Grande do Sul - UFRGS; Master of Laws (LLM) pela University of Warwick; mestre em Direito Privado pela UFRGS; advogado e professor do Programa de Pós-graduação em Direito da Universidade Luterana do Brasil - ULBRA

** Mestre em Direitos Fundamentais pela Universidade Luterana do Brasil - ULBRA; especialista em Direito do Trabalho pela Universidade do Vale do Rio dos Sinos UNISINOS
} 
de regra, sinônimo de boa administração em sentido empregado pela Ciência Econômica e Administrativa, ou seja, o de obter o melhor resultado possível com a menor despesa (medida típica da relação entre custo e benefício).

Em segundo lugar, far-se-á análise da jurisprudência do Tribunal de Justiça do Estado do Rio Grande do Sul (TJRS) a respeito dos sentidos que são atribuídos à eficiência pelos julgadores. Foram pesquisados 100 acórdãos no site do Tribunal (www.tj.rs.gov.br), prolatados durante o período de 01/01/05 a 23/02/07 e relativos ao assunto, em que apareceram as palavras-chave eficiência e princípio da eficiência, relacionadas à gestão pública. $\mathrm{O}$ resultado, como se demonstrará no item 2, foi que o Poder Judiciário gaúcho entende, majoritariamente, a eficiência ser sinônimo de boa administração, porém com conotação diversa daquela defendida pela majoritária doutrina jurídica. O entendimento predominante no TJRS é o de que a eficiência não seja o melhor resultado possível diante do contexto orçamentário (análise de custo e benefício), mas no sentido de qualidade do serviço público prestado.

\section{Conceito de eficiência}

A eficiência adquiriu grande importância no Direito, especialmente após o advento da Emenda Constitucional 19, de 4.6.1998, a qual a acrescentou como princípio que rege a Administração Pública no caput do artigo 37 da Constituição Federal. Sua origem é a Mensagem Presidencial 886/95, que restou convertida na Proposta de Emenda Constitucional 173/95, cuja conclusão foi a EC 19/98. Apareceu também como princípio no caput do artigo $2^{\circ}$ da Lei 9.784, de 29.1.1999, que trata do processo administrativo federal. A Lei 8.987, que é de 1995, ou seja, anterior à EC 19/98, já fazia referência ao mencionado princípio, por exemplo, no $\S 1^{\circ}$ do artigo $6^{\circ}$.

A literatura jurídica faz distinção entre eficiência e eficácia ${ }^{1}$. Por exemplo, na visão de Torres $^{2}$, eficácia é a concreção dos objetivos desejados por determinada ação do Estado, não sendo levados em consideração os meios e os mecanismos utilizados para tanto. Assim, o Estado pode ser eficaz em resolver o problema do analfabetismo no Brasil, mas pode estar fazendo isso com mais recursos do que necessitaria. Na eficiência, por sua vez, há clara preocupação com os mecanismos que foram usados para a obtenção do êxito na atividade do Estado. Assim, procura-se buscar os meios mais econômicos e viáveis, para maximizar os resultados e minimizar os custos. Em suma: é atingir o objetivo com o menor custo e o melhor resultado possíveis.

\footnotetext{
${ }^{1}$ Não entraremos na distinção kelseniana entre eficácia jurídica e social, sendo a primeira a adequação das normas jurídicas de acordo com os pressupostos legais e lógicos do sistema jurídico, e a segunda, a adequação social às normas.

2 TORRES, Marcelo Douglas de Figueiredo. Estado, democracia e administração pública no Brasil. Rio de Janeiro: Fundação Getúlio Vargas, 2004. p. 175.
} 
No mesmo diapasão, Sztajn ${ }^{3}$ define eficiência assim: "Eficiência significa a aptidão para obter o máximo ou o melhor resultado ou rendimento, com a menor perda ou o menor dispêndio de esforços; associa-se à noção de rendimento, de produtividade; de adequação à função." Ressalta, por fim, que a eficácia, por sua vez, é a aptidão para produzir efeitos.

Esta mesma linha de raciocínio é compartilhada por Dinorá. Além de distinguila da eficácia, a jurista paulista faz um liame da eficiência com a qualidade na prestação do serviço público. Salienta desta forma: ${ }^{4}$

É um conceito econômico, que introduz, no mundo jurídico, parâmetros relativos de aproveitamento ótimo de recursos escassos disponíveis para a realização máxima de resultados desejados. Não se cuida apenas de exigir que o Estado alcance resultados com os meios que lhe são colocados à disposição pela sociedade (eficácia), mas de que os efetue o melhor possível (eficiência), tendo, assim, uma dimensão qualitativa.

$[\ldots]$

A eficiência diz respeito ao cumprimento das finalidades do serviço público, de molde a satisfazer necessidades dos usuários, do modo menos oneroso possível, extraindo-se dos recursos empregados a maior qualidade na sua prestação.

Nos posicionamentos expostos, percebe-se diferenciação entre eficácia e eficiência, sendo que a primeira se refere à capacidade de produção de resultados, enquanto a segunda é a busca pelo melhor resultado possível aliada ao menor gasto de forças possível. Preserva-se, desse modo, a origem econômica de eficiência constitucional, e, com isso, abre-se importante espaço de diálogo entre Direito e Economia.

Freitas ${ }^{5}$ sustenta que “[...] o administrador público está obrigado a obrar tendo como parâmetro o ótimo [...]". Cabe a ele procurar encontrar a solução que seja a melhor possível sob o ponto de vista econômico.

No mesmo diapasão, Härger ${ }^{6}$, nos casos em que o gestor público tenha certa margem de discricionariedade, é sua obrigação constitucional procurar encontrar a melhor solução possível para que o interesse público seja corretamente atendido. Seria nos atos administrativos discricionários que o Princípio da Eficiência teria sido efetivamente sobrevalorizado pelo constituinte, pois embasaria a atuação do administrador público. Aliás,

${ }^{3}$ ZYLBERSZTAJN, Décio; SZTAJN, Rachel (Org.). Direito e economia. Rio de Janeiro: Campus, 2005. p. 83.

${ }^{4}$ GROTTI, Dinorá Adelaide Musetti. O Serviço público e a constituição brasileira de 1988. São Paulo: Malheiros, 2003. p. 298-299.

5 FREITAS, Juarez. O controle dos atos administrativos e os princípios fundamentais. 2. ed. São Paulo: Malheiros, 1999. p. 85.

${ }^{6}$ HÄRGER, Marcelo. Reflexões iniciais sobre o princípio da eficiência. Disponível em: <http://www. hargeradvogados.com.br>. Acesso em: 29 mai. 2007. Disponível também: HÄRGER, Marcelo. Reflexões Iniciais sobre o Princípio da Eficiência, Revista de Direito Administrativo, Rio de Janeiro, n. 217, p.151161, dez. 1999. 
em primeiro momento, o Princípio da Eficiência poderia ser confundido, inclusive, com os Princípios da Moralidade e da Razoabilidade da Administração. Härger, todavia, descarta esta hipótese no mesmo trecho:

Apesar disso, possui conteúdo próprio. Traduz o dever de administrar, não só de modo razoável e conforme a moral, mas utilizando as melhores opções disponíveis. É o dever de alcançar a solução que seja ótima ao atendimento das finalidades públicas. Não basta que seja uma solução possível. Deve, isto sim, ser a melhor solução. Há um dever jurídico de boa administração para o atendimento da finalidade legal.

Torres $^{7}$ explica que a eficiência era um dos objetivos do Plano Diretor da Reforma do Estado, cuja implementação caberia ao recém-criado Ministério da Administração Federal e Reforma do Estado - MARE. O plano foi apresentado pelo então Presidente da República, Fernando Henrique Cardoso, à sociedade em meados de novembro de 1995. Os principais nomes a ser destacados são os do ex-ministro do MARE, Sr. Luiz Carlos Bresser Pereira, e da ex-secretária executiva do MARE, Sra. Cláudia Costin. Naquela época, expressões, como choque de gestão e qualidade no serviço público, eram comuns e serviram de embasamento para a inclusão do Princípio da Eficiência no texto constitucional.

É certo que a inserção do Princípio da Eficiência no caput do artigo 37 da CF pela EC 19/98 decorreu da clara intenção de reformar o Estado. De acordo com Egon Bockmann Moreira ${ }^{8}$, o Princípio da Eficiência passou a constituir verdadeira diretriz para a Administração Pública. A inclusão no texto constitucional, segundo ele, resultou da reforma gerencial do Estado, a qual pretendia acabar com a "administração burocrática" e instalar a "Administração Pública Gerencial no Brasil”. Lembra o ex-consultor jurídico do MARE que o Princípio da Eficiência possui outros nomes na doutrina estrangeira, tais como, Princípio da Eficácia (art. 103, 1, da Constituição da Espanha) e Princípio do Bom Andamento ou da Boa Administração (art. 97 da Constituição da Itália).

A reforma do Estado buscava melhorar sua organização, seus servidores, suas finanças e seu sistema institucional-legal, proporcionando relação mais harmoniosa com a sociedade civil. A partir do advento da Reforma, consoante Torres, ${ }^{9}$ o núcleo estratégico do Estado tomaria decisões mais adequadas e ofereceria serviços públicos que operassem com maior eficiência. Nesse diapasão, houve a idealização de contratos de gestão, agências autônomas e organizações sociais para que conferissem efetividade à reforma estatal. Somado a isso houve a combinação de um programa de "desestatização", pelo qual várias empresas estatais foram vendidas e submetidas a regras de mercado, assumindo o Estado um papel de agente regulador desses novos mercados.

7 TORRES, Marcelo Douglas de Figueiredo. Estado, democracia e administração pública no Brasil. Rio de Janeiro: Fundação Getúlio Vargas, 2004. p. 172.

8 MOREIRA, Egon Bockmann. O Princípio da Eficiência e a Lei 9.784/99. Revista da Procuradoria Geral do INS, Brasília, v. 7. n. 3, p. 49-51, out./dez. 2000.

9 TORRES, Marcelo Douglas de Figueiredo. Estado, democracia e administração pública no Brasil. Rio de Janeiro: Fundação Getúlio Vargas, 2004. p. 172-174. 
Houve, portanto, segundo este entendimento, a intenção de implantar, no país, novo modelo de Estado, o chamado Estado gestor ou, por outros, chamado de Estado regulador. Neste aspecto, vale destacar o seguinte trecho de artigo de Steinmetz: ${ }^{10}$

Ainda que sem muita pressão, já há referências a um novo modelo (de Estado): o Estado regulador. Bresser Pereira (1996, p. 285), por exemplo, prevê que o Estado moderno do século XXI “[...] deverá ser um Estado regulador e transferidor de recursos, que garante o financiamento a fundo perdido das atividades que o mercado não tem condições de realizar". Um Estado que não será próximo do mínimo (século XIX) nem executor (século XX).

$[\ldots]$

Ainda, segundo Puceiro, para que o Estado exerça com sucesso seu poder regulador, são necessários quadros regulatórios claros - que estabeleçam as regras que irão reger as relações entre o Estado e as empresas prestadoras de serviços públicos e entre estas e os usuários - e poder de polícia que garanta aos beneficiários e aos usuários a prestação dos serviços.

Gabardo ${ }^{11}$ parece destoar ligeiramente desse quase consenso que se forma entre juristas, quanto ao influxo da Economia sobre o Direito Administrativo, mediante o Princípio da Eficiência. Parece preferir a análise tradicional dos juristas constitucionalistas, de caráter mais dogmático (e de influência alemã), buscando analisar a força constitucional da nova redação ao artigo 37 da Constituição Federal, muito embora não pareça rejeitar, peremptoriamente, a influência das categorias econômicas na definição de eficiência. Em todo caso, a literatura jurídica especializada defende a clara influência da racionalidade econômico-gerencial à máquina governamental, portanto, ao Direito Público, abrindo espaço para o diálogo entre o Direito e a Economia (ou a "interconexão sistêmica" para os que gostam da análise de Luhmann). ${ }^{12}$

Sztajn ${ }^{13}$ observa que a relação entre Direito e Economia é muito antiga, mas que não lhe foi dada a importância necessária, ainda que possa oferecer soluções para questões atuais. Iniciou-se a percepção da necessidade de recorrer-se à avaliação econômica na formulação de normas jurídicas, a fim de torná-las mais eficientes e mais eficazes. Foi a partir dos anos 60 do século passado que se iniciou o desenvolvimento da chamada de Análise Econômica do Direito (Law and Economics). Acrescenta a autora na mesma passagem:

O movimento começa a ganhar corpo com a publicação de The Problem of Social Cost, de Ronald H. Coase, professor da Universidade de Chicago,

${ }^{10}$ STEINMETZ, Wilson. Premissas para uma Adequada Reforma do Estado. Revista Direito e Democracia, Canoas, v. 5, p. 81-82. 2004.

${ }^{11}$ GABARDO, Émerson. Princípio constitucional da eficiência administrativa. São Paulo: Dialética, 2002. p. 86-88.

${ }^{12}$ A literatura norte-americana é farta sobre o assunto, mas nesse artigo estamos preocupados com a literatura jurídica nacional. Para referências ulteriores, ver o nosso TIMM, Luciano (Org.). Direito e Economia. São Paulo: THOMSON-IOB, 2005.

${ }^{13}$ SZTAJN, op. cit., p. 74-75. 
passa por Richard Posner, com Economic Analysis of Law, ambos professores da Universidade de Chicago, por The Cost of Accidents de Guido Calabresi, de Yale. Além deles, Henry Manne, George Stigler, Armen Alchian, Steven Medema, Oliver Wiliamson, entre outros, aprofundam o diálogo.

Fonseca ${ }^{14}$ menciona que foi Posner o principal propulsor da Análise Econômica do Direito e quem deu abordagem ampla e profunda ao Princípio da Eficiência. Segundo Fonseca, Posner defendia que a economia normativa ditaria a lei para o legislador, para o juiz e para o intérprete. Logo, não estaria destituída de escala de valores, contaminando-se pelos valores fixados pela política, pela moral e pelo direito. A eficiência seria o fundamento dessa escala de valores e um dos sentidos da justiça, na medida em que o homem é um maximizador racional de seus objetivos de vida. Continua Fonseca, ao explicar o pensamento de Posner:

Os instrumentos de que se serve nessa avaliação são as noções de preço, custo, custo das oportunidades, de gravitação dos recursos em direção a um uso mais vantajoso. Para Posner, a eficiência é a utilização dos recursos econômicos de modo que o valor, ou seja, a satisfação humana, em confronto com a vontade de pagar por produtos ou serviços, alcance o nível máximo, através da maximização entre os custos e as vantagens.

Conforme o jurista brasileiro, ${ }^{15}$ a atuação do Estado deve ser pautada pelo Princípio da Eficiência e, ao fazê-lo, deve observar três planos: a) aquele em que ele próprio exerce atividade econômica definida pela $\mathrm{CF}$; b) aquele em que adota atitude normativa da atividade econômica; c) aquele em que estimula, ou favorece, ou planeja a atividade econômica. Completa o autor: "É óbvio que o mesmo princípio deverá informar a atividade das empresas, que, ao exercerem a atividade econômica, devem estar imbuídas da idéia de que o seu sucesso depende exatamente da eficiência das posturas adotadas."

No jargão dos economistas, um dos modelos de eficiência social está vinculado ao chamado "Ótimo de Pareto" (ou a Eficiência de Pareto), ou seja, aquela situação em que alguém melhora a sua utilidade, sem prejudicar a utilidade de terceiro. Portanto, a gestão eficiente seria a que melhor gastaria os recursos, isto é, aquele gasto que não poderia alternativamente trazer maior benefício ou utilidade para a sociedade, já que não faria alguém melhor, sem prejudicar outrem. Alvarez ${ }^{1616}$ explica o Ótimo de Pareto desse modo: "Uma decisão é ótima, segundo Pareto, se não existe outra situação diferente que se prefira unanimemente, o que implica que devem rejeitar todas as situações que todos declaram unanimemente como piores."

É nesse sentido que a melhor literatura jurídica se refere ao princípio da eficiência no âmbito do Direito Administrativo. O Estado deve abster-se de fazer opções de gastos que não tragam

\footnotetext{
${ }^{14}$ FONSECA, João Bosco Leopoldino da. Direito econômico. 2. ed. Rio de Janeiro: Forense, 1998. p. 36-37.

${ }^{15}$ Ibidem, p. 35-36.

${ }^{16}$ ALVAREZ, Alejandro Bugallo. Análise econômica do direito: contribuições e desmistificações. Direito Estado e Sociedade, v. 9, n. 29, jul./dez. 2006. p. 63.
} 
benefício à maioria da coletividade. Isso aconteceria ainda que não houvesse um serviço público de qualidade. Qualidade e eficiência são conceitos distintos na Economia e, conseqüentemente, no Direito, quanto importa estas categorias econômico-gerenciais e dota-os de caráter normativo.

Exemplificativamente, um hospital ou uma escola pública podem ser eficientes, ao receber poucos recursos governamentais, mas atender o máximo número viável de pessoas (relação entre custo e benefício). No entanto, o serviço (educação ou atendimento) podem não ser de qualidade e satisfazer os consumidores. Ou, em outras situações, determinado serviço pode ser prestado com qualidade (como universidades públicas gratuitas), mas não significa eficiência no emprego dos recursos - pode ser que a relação entre professor e aluno seja baixa, ou que o nível de produção científica seja insuficiente frente aos investimentos feitos.

Na opinião da maioria dos juristas, portanto, o Princípio Constitucional da Eficiência Administrativa não deixa dúvidas de que cabe à Administração Pública e aos particulares que prestam serviços públicos concedidos fazer o melhor possível na equação custo-benefício, para cumprir com a sua atribuição de acordo com os critérios dados pela Ciência Econômica. Sintetiza bem isso em favor da interpretação econômica da eficiência a opinião de Galdino:1717

De outro lado, abriu-se a possibilidade de utilização de fundamentos e justificativas antes atreladas aos princípios da proporcionalidade [...], da moralidade, da impessoalidade ou ao próprio dever de boa administração para referi-los à eficiência - uma espécie de migração de fundamentos antes atrelados a outros princípios constitucionais e agora referidos à eficiência. Essa correlação e construção devem representar uma delimitação tanto quanto possível precisa dos limites de atuação de cada princípio.

Prima facie, parece acertada a assertiva de que o princípio da eficiência representa acentuada relação com a idéia de proporcionalidade ou mesmo com idéia de razoabilidade.

Com efeito, assim como a razoabilidade importa na aferição da relação entre os meios e os fins resultantes de determinada medida, a eficiência implica a verificação de que os resultados alcançados por uma medida são representativos de uma relação custo-benefício favorável em relação aos meios empregados e aos sacrifícios impostos - essa é, inclusive, a noção corrente de eficiência, que deve ser juridicamente temperada através de parâmetros éticos.

\section{Estudo da jurisprudência do TJRS}

Mais importante que a opinião dos juristas (law on the books) é o direito vivo da jurisprudência (law in action). No item 1 deste artigo, foram apresentadas algumas definições de

${ }^{17}$ GALDINO, FLÁVIO. Introdução à teoria dos custos dos direitos: direitos não nascem em árvores. Rio de Janeiro: Lumen Juris, 2005. p. 258-259. 
eficiência defendidas pela doutrina jurídica, mostrando a necessidade do diálogo entre as ciências jurídicas e econômicas. Nesse ponto, cabe ressaltar qual é o sentido de eficiência comumente atribuído pelo Poder Judiciário do Rio Grade do Sul.

Para chegar-se a uma conclusão satisfatória (ainda que não perfeitamente científica se consideradas as regras estatísticas, que exigiriam maior controle de variáveis e de outros elementos que fogem ao escopo da discussão), a pesquisa foi realizada no site oficial do Tribunal de Justiça do Estado do Rio Grande do Sul (www.tj.rs.gov.br). Foram pesquisados 100 acórdãos prolatados durante o período compreendido entre $01 / 01 / 05$ e 23/02/07, os quais foram localizados por meio das palavraschave eficiência e princípio da efetividade e que guardavam relação com a administração pública. Desse total, 88 acórdãos atribuíam à eficiência o sentido de boa administração, mas entendida como "qualidade na prestação do serviço público" e não no sentido empregado pela ciência econômica vista na primeira parte do artigo. A título ilustrativo, pode ser citada a apelação cível n ${ }^{0} 70018350967$, apreciada pela $18^{\text {a }}$ Câmara Cível em 08 de fevereiro de 2007:

APELAÇÃO CÍVEL. AÇÃO DECLARATÓRIA DE NULIDADE.
TELEFONIA FIXA. BRASIL TELECOM. TARIFA BÁSICA MENSAL.
COBRANÇA. POSSIBILIDADE. PRELIMINAR SUSCITADA EM
CONTRA-RAZÕES DE APELAÇÃO REJEITADA. SENTENÇA DE
IMPROCEDÊNCIA CONFIRMADA. CHAMAMENTO DA ANATEL
AO FEITO. Falece interesse ao poder concedente em integrar o pólo passivo
de lide onde se discute questão pertinente à validade da tarifa cobrada pela
concessionária. MÉRITO. Não há ilegalidade ou abusividade na cobrança da
denominada tarifa básica mensal, a qual encontra previsão na Lei 9.472/97, na
resolução 85/98 da ANATEL e nas Portarias $217 / 97$ e $226 / 97$ do Ministério das
Comunicações. Tarifa que se destina ao ressarcimento dos custos operacionais
de manutenção, atualização e modernização da infra-estrutura da rede de
telefonia, indispensável à continuidade, qualidade e eficiência do serviço.
PRELIMINAR REJEITADA. RECURSO IMPROVIDO. UNÂNIME.
(Apelação Cível No 70018350967 , Décima Oitava Câmara Cível, Tribunal
de Justiça do RS, Relator: Cláudio Augusto Rosa Lopes Nunes, Julgado em
08/02/2007)

Trata-se de ação declaratória de nulidade de cobrança cumulada com repetição de indébito ajuizada por uma consumidora contra a Brasil Telecom S.A., na comarca de Passo Fundo. A julgadora a quo considerou a ação improcedente, pois entendeu que haveria legalidade na cobrança da tarifa básica mensal. Irresignada, a autora recorreu. O relator, desembargador Cláudio Augusto Rosa Lopes Nunes, rejeitou o apelo da demandante aduzindo que a cobrança da tarifa básica mensal, além de possuir amparo normativo, tem como objetivo o ressarcimento dos custos operacionais da rede de telefonia. Pensar diferente, segundo se conclui do julgado, significaria prejudicar a qualidade e a eficiência da prestação do serviço público concedido. Percebe-se que a Câmara claramente atribuiu à eficiência o sentido de boa qualidade na prestação do serviço público. No seu entender, decisão divergente causaria prejuízos à prestação do serviço público. A decisão confunde, como dito, qualidade com eficiência. 
$\mathrm{Na}$ mesma linha de entendimento, a $3^{\mathrm{a}}$ Câmara Cível negou provimento à apelação no 70014119440 do Departamento Estadual de Estradas de Rodagem - DAER numa ação anulatória de penalidade por infração de trânsito interposta pelo proprietário do veículo na comarca de Espumoso. O julgador a quo já havia decidido pela procedência da ação, anulando tanto o auto de infração quanto a multa aplicada e condenando o DAER ao pagamento de indenização por danos morais, no valor de 5 salários mínimos. A autarquia estadual recorreu, aduzindo que o veículo do demandante fora multado por engano, em razão da existência de problemas técnicos no controlador eletrônico de velocidade, que já tinham sido corrigidos de imediato, caracterizando a carência de ação do autor por ausência de pretensão resistida. No entendimento da desembargadora, relatora Matilde Chabar Maia, a conduta administrativa mostrou-se equivocada desde o início, ao identificar, erroneamente, a placa do veículo, fato que caracterizou falta de ineficiência. O vocábulo eficiência foi utilizado novamente como sinônimo de boa administração ou de prestação do serviço público com qualidade. Eis a ementa do aludido acórdão:

APELAÇÃO CÍVEL. AÇÃO ANULATÓRIA DE PENALIDADE POR INFRAÇÃO DE TRÂNSITO. Equívoco do DAER ao identificar a placa do veículo infrator. Recurso administrativo do autor indeferido. Reconhecimento do erro somente depois de deferida a liminar e apresentada réplica. Carência de ação afastada. Dano moral caracterizado. Conduta administrativa desde o início viciada pela desídia. Inobservância do dever de eficiência. Paz jurídica violada a merecer compensação. Fixação em quantia equivalente a cinco salários mínimos. Verba honorária mantida em $15 \%$ sobre o valor atribuído à causa - valor de alçada -. Negaram provimento à apelação. (Apelação Cível No 70014119440, Terceira Câmara Cível, Tribunal de Justiça do RS, Relator: Matilde Chabar Maia, Julgado em 26/10/2006)

A terceira decisão é relativa a uma empresa do ramo de celulares que moveu ação contra o município de Porto Alegre, com o intuito de obrigá-lo a manifestar-se sobre o pedido de licenciamento para a instalação e a operação de estação de rádio-base, abstendo-se de cominar penalidade enquanto estivesse pendente a situação. A demanda continha pedido de antecipação de tutela, o qual foi negado pelo julgador a quo. Da decisão foi interposto agravo de instrumento $n^{0} 70016905168$ pela empresa. A $21^{\text {a }}$ Câmara Cível entendeu por provê-lo, por maioria. $\mathrm{O}$ administrado havia feito pedido de licenciamento. Adotando posição inerte, a Administração Pública não se manifestou sobre o requerimento, levando o autor a ingressar com ação de obrigação de fazer. O desembargador Genaro José Baroni Borges entendeu que não teria sido prestado serviço público de forma eficiente. A eficiência foi utilizada, novamente, como sinônimo de boa administração ou de prestação de serviço público de qualidade. Esta é a sua ementa:

AGRAVO. DIREITO PÚBLICO. AÇÃO DE OBRIGAÇÃO DE FAZER. MANIFESTAÇÃO DA ADMINISTRAÇÃO ACERCA DE PEDIDO DE LICENCIAMENTO. Ostenta-se ilegal a conduta omissiva da Administração 
que se recusa conceder ou negar licença. $\mathrm{O}$ dever de eficiência, erigido à categoria de princípio norteador da atividade administrativa (CF- art. 37), impõe seja exercida com presteza, exigindo não só resultados positivos para o próprio serviço, mas satisfatório atendimento ao administrado, que por isso não pode aguardar "ad aeternum" a manifestação do Poder Público, por mais complexas as várias etapas administrativas a vencer, com vistas, para ficar no caso, à concessão da licença. Agravo provido, por maioria. (Agravo de Instrumento No 70016905168, Vigésima Primeira Câmara Cível, Tribunal de Justiça do RS, Relator: Genaro José Baroni Borges, Julgado em 08/11/2006)

Resta evidenciado que o sentido atribuído à eficiência pela jurisprudência do TJRS está um pouco distante do que a Economia estipula, portanto aquém da doutrina administrativa. Talvez, se a jurisprudência atribuísse à eficiência o sentido que a Economia propôs originalmente (obtenção do melhor resultado possível com o menor custo possível), o princípio acrescentado à Carta Maior pela Emenda Constitucional no 19/98 teria a sua efetividade plena.

Exemplificamos: o Poder Judiciário, ao realizar o julgamento de ação relativa a serviço público licitado, verificaria se, quando da realização da licitação, o assunto debatido no processo foi objeto de contratação com o particular (pense-se em acidentes em estradas exploradas por concessionárias em que determinados tipos de danos podem não ter sido contratados, como aqueles derivados de assaltos em praças de pedágio). $O$ fato de alguém ser assaltado não significa que houve ineficiência na prestação do serviço da concessionária.

Eficiência é o melhor resultado possível para a coletividade, diante de uma equação de custo e benefício. Inclusive, pode ser que este tipo de dano fosse coberto no contrato, geraria custo adicional ao usuário no pedágio (para pagar a apólice de seguros para este tipo de sinistro) que poderia inviabilizar algumas atividades comerciais dependentes do transporte viário ou poderia dificultar o trânsito de pessoas de menor baixa renda, menos expostas aos riscos daquele tipo de sinistro.

Esse guia interpretativo é particularmente importante no controle ex ante de licitações de obras e de serviços públicos. Ou seja, antes da contratação da concessionária ou da empreiteira, verificar-se-ia se o custo da obra ou do serviço é adequado para os fins a que o ato se propõe a atingir. Por exemplo, é freqüentemente comentado pelos paulistanos que um túnel de São Paulo teve o custo por metro quadrado superior ao custo do túnel do Canal da Mancha. Verdadeira ou não a anedota, não passaria no teste da eficiência já quando da fase da licitação.

Portanto, ao discutir eficiência, não se ingressaria no mérito propriamente dito do ato administrativo (construir ou não uma ponte sobre um rio, por exemplo), o qual caberia, exclusivamente, ao Poder Executivo, mas sim seria verificado se a decisão foi a que alcançou a melhor relação de custo e benefício possível (a ponte foi construída de acordo com parâmetros satisfatórios do ponto de vista da engenharia, e o seu custo estava pouco abaixo da média de mercado, por exemplo). Acreditamos que, sob esse prisma, seria conferido o sentido econômico à eficiência, fato que favoreceria o melhor 
aproveitamento dos recursos públicos, que são, por definição, escassos. Isso, no país dos desperdícios, acarretaria justiça com os que mais necessitam da ação do Estado.

\section{Conclusão}

A eficiência, consoante o sentido econômico, consiste em obter o melhor resultado possível com o menor custo possível, com o que parecem concordar os administrativistas pesquisados, pelo menos no plano teórico. No plano prático de aplicação dos conceitos aos casos concretos, a jurisprudência majoritária do TJRS parece ter atribuído ao princípio da eficiência conotação diversa. A idéia corrente é a de que a eficiência está vinculada à boa administração no sentido de qualidade na prestação do serviço público.

A eficiência, no entanto, não significa necessariamente qualidade. Se, por exemplo, os recursos à saúde forem escassos, mas, mesmo assim, houver número grande de atendimentos com poucos erros na execução dos serviços (boa relação de custo e benefício), haverá eficiência, todavia não haverá necessariamente qualidade do serviço público. Para a correta aplicação do princípio da eficiência, há a necessidade de os juízes receberem treinamento sobre finanças e economia (assim como obterem assessores especializados, como se vê hoje, por exemplo, no Ministério Público). Desse modo, poderão aferir a relação de custo e benefício do gasto público quando surgir, em juízo, a discussão da eficiência administrativa, evitando a analogia com qualidade no serviço.

\section{Abstract}

The principle of efficiency wasadded to the text of Section 37 of the Brazilian Federal Constitutional of 1988 in amendments made on 1998's reforms. The paper deals with a survey on legal scholarship that face this subject (law on the books) and also a case study onprecedents of the Court of Appeals from the State of Rio Grande do Sul (law in action). The conclusion was that the legal scholars are closer than courts to the concept of efficiency as used by economists (i.e., cost benefit analysis).

Key words: Efficiency. Brazilian FederalConstitution, Section 37. Public service.

\section{Referências}

ALVAREZ, Alejandro Bugallo. Análise econômica do direito: contribuições e desmistificações. Direito Estado e Sociedade, v. 9, n. 29, p. 49-68, jul./dez. 2006.

CANOTILHO, José Joaquim Gomes; MOREIRA, Vital. Constituição da República Portuguesa anotada. 3. ed. Coimbra: Coimbra Editora, 1993. 
FONSECA, João Bosco Leopoldino da. Direito econômico. 2. ed. Rio de Janeiro: Forense, 1998.

FREITAS, Juarez. O controle dos atos administrativos e os princípios fundamentais. 2. ed. São Paulo: Malheiros, 1999.

GABARDO, Émerson. Princípio constitucional da eficiência administrativa. São Paulo: Dialética, 2002.

GALDINO, Flávio. Introdução à teoria dos custos dos direitos: direitos não nascem em árvores. Rio de Janeiro: Lumen Juris, 2005.

GRAU, Eros Roberto. A ordem econômica na constituição de 1988. 3. ed. São Paulo: Malheiros, 1997.

GROTTI, Dinorá Adelaide Musetti. O serviço público e a cConstituição brasileira de 1988. São Paulo: Malheiros, 2003.

HÄRGER, Marcelo. Reflexões iniciais sobre o princípio da eficiência. Revista de Direito Administrativo,, Rio de Janeiro, n. 217. p.151-161. dez. 1999. Disponível também em <http:// www.hargeradvogados.com.br>. Acesso em 29 mai. 2007.

LOUREIRO, João Carlos Simões Gonçalves. O procedimento administrativo entre a eficiência e a garantia dos particulares (Algumas Considerações). Coimbra: Coimbra, 1995.

MOREIRA, Egon Bockmann. O Princípio da Eficiência e a Lei 9.784/99. Revista da Procuradoria Geral do INSS, Brasília, v. 7. n. 3, p. 45-60. out./dez. 2000.

. O direito administrativo contemporâneo e a intervenção do estado na ordem econômica. Revista Eletrônica de Direito Administrativo Econômico - REDAE. Salvador, Instituto de Direito Público da Bahia, n. 1. p. 1-23. fevereiro. 2005. Disponível em: <http://www.direitodoestado. com.br>. Acesso em: 17 jul. 2007. p. 20.

OHLWEILER, Leonel Pires. O contributo da jurisdição constitucional para a formação do regime jurídico-administrativo. Revista do Instituto de Hermenêutica Jurídica, v. 1, n. 2, 2004.

STEINMETZ, Wilson. Premissas para uma Adequada Reforma do Estado. Revista Direito e Democracia, Canoas, v. 5, p. 71-84. 2004.

TORRES, Marcelo Douglas de Figueiredo. Estado, democracia e administração pública no Brasil. Rio de Janeiro: [s.n.], 2004.

VELJANOVSKI, Cento. A economia do direito e da lei: uma introdução. Tradução de Francisco J. Beralli. Rio de Janeiro: Instituto Liberal, 1994.

ZYLBERSZTAJN, Décio; SZTAJN, Rachel (Org.). Direito e economia. Rio de Janeiro: Campus, 2005. 